\title{
ANÁLISIS AXIOLÓGICO-EDUCATIVO DE VIDEOJUEGOS DE TEMÁTICA VIOLENTA
}

Resumen. Un alto porcentaje de los videojuegos existentes en el mercado poseen argumentos relacionados con el ejercicio de la violencia física y psicológica. Ciertos estudios indican que este tipo de juegos son masivamente utilizados por niños y adolescentes, lo que reabre la polémica de la posible influencia en la conformación de su personalidad y, de manera especial, en la construcción de la escala de valores que orientará sus conductas presentes y futuras como ciudadanos.

Este trabajo recoge los resultados parciales de una reciente investigación en la que videojugadores adultos relacionados con el mundo de la educación (futuros docentes en formación) han analizado críticamente la componente axiológica de un nutrido grupo de videojuegos de acción que ocupan destacados puestos en las listas de ventas. Para ello se ha utilizado una escala específica, suministrada para tal fin, que contiene indicadores alusivos a aspectos sustanciales tales como su argumento, los videos inicial y final, los comportamientos de sus protagonistas, la escenografía y el atuendo los personajes, las acciones que realiza el jugador y los resultados parciales y finales conseguidos.

Palabras clave: Videojuegos, violencia física y psicológica, valores, educación ética y ciudadana y cultura de paz.
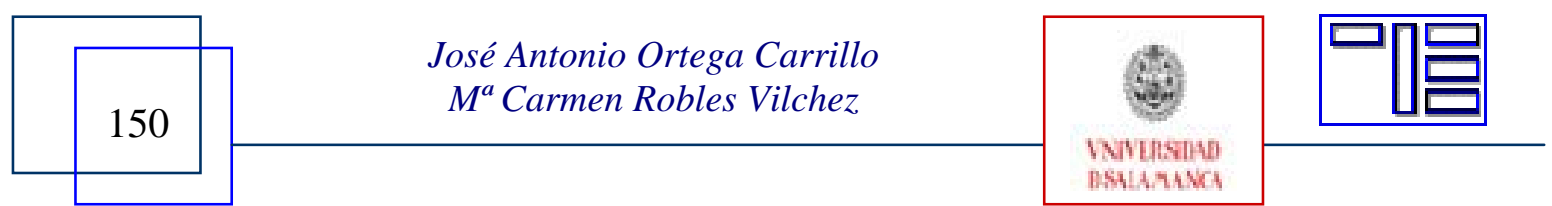


\section{AXIOLOGICAL AND EDUCATIONAL ANALYSIS OF VIDEO-GAMES WITH VIOLENCE CONTENTS}

Abstract. A high percentage of video-games now in the market have contents related with physical and psychological violence. There are investigations that show that this kind of games is mainly used by children and adolescents. This fact reinitiates the polemic of the possible influence in the formation of their personality and, very specially, in the construction of the value scale that will direct their present and future behaviour as citizens.

This paper shows the partial results of a recent research in which adult players related with the education area (future teachers) analyzed critically the axiological component of a very important group of video-games which are important in the sales lists. For that purpose, a very specific scale has been used, with indicators related to the argument, the initial and final videos, the protagonist's behaviour, the stenography, clothes, actions and partial and final results obtained by players.

Keywords: video-games, physical and psychological violence, values, etic and citizenship education, culture of peace.

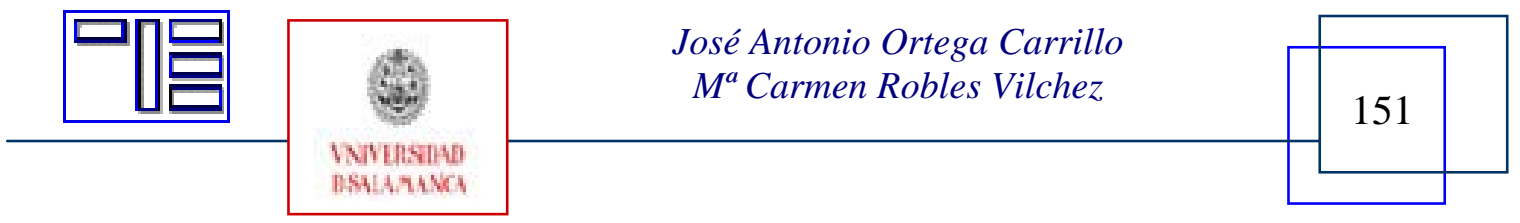




\section{ANALYSE AXIOLÓGIQUE ET ÉDUCATIF DE JEUX VIDÉO DE THÈME VIOLENTE}

Sommaire: Un grand pourcentage des jeux vidéo existants dans le marché possèdent argumenter liés à l'exercice de la violence physique et psychologique. Certaines études et adolescents indiquent que ce type de jeux est massivement utilisé par enfants, ce qu'il rouvre la polémique de la possible influence dans la conformation de sa personnalité et, de manière spéciale, dans la construction de l'échelle de valeurs qu'il orientera ses conduites présentes et futures comme citadins.

Cette travail ramasse les résultats partiels d'une récente investigation ou les vidéo joueur adultes liés au monde de l'éducation (futurs enseignant en formation) ont analysé critiquement la composant de valeurs d'un nourri groupe de jeux vidéo d'action qu'ils occupent remarquables positions dans les listes de ventes. Pour cela on a utilisé une échelle spécifique, fournie pour telle fin, qui contient pointeurs allusifs aux aspects substantiels tels comme son argumenter, les vidéos initial et final, les conduites de ses protagonistes, la mise en scène et la mise du personnages, les actions qu'il réalise, le joueur et les résultats partiels et fins obtenues.

Mots clefs: Jeux vidéo, violence physique et psychologique, valeurs, éducation étique et citoyenneté, culture de paix.



\title{
ANÁLISIS AXIOLÓGICO-EDUCATIVO DE VIDEOJUEGOS DE TEMÁTICA VIOLENTA
}

\author{
José Antonio Ortega Carrillo \\ jaorte@ugr.es \\ M Carmen Robles Vilchez \\ mcrobles@ugr.es \\ Universidad de Granada
}

\section{INTRODUCCIÓN: INFANCIA Y CONSUMO DE VIDEOJUEGOS VIOLEN- TOS}

La utilización por los niños y adolescentes de los videojuegos es un tema que preocupa e interesa tanto a padres y madres como al profesorado. A unos por el tiempo que sus hijos les pueden dedicar dejando de hacer otras actividades y por la influencia en sus valores y conductas que sobre ellos puedan ejercer; a otros, por el desconocimiento que sobre ellos tienen y por la competencia, en términos de motivación e interés, que suponen frente a las tareas propias de su escolaridad (Pascual y Ortega, 2007).

Un interesante trabajo de Max Ferzzola (2007), titulado "La historia de la violencia en los videojuegos", pone de manifiesto como desde 1976 hasta nuestros días, el número de videojuegos de temática violenta han ido creciendo exponencialmente, a la vez que ha aumentado hasta límites insospechados el impacto emocional que ejercen sobre los jugadores, convirtiéndose actualmente en uno de los géneros de mayor consumo en los países desarrollados.

Tales afirmaciones son corroboradas por las estadísticas anuales de ventas que publican las empresas del sector, así como por investigaciones, como la realizada en 2005 en España por la Asociación "Protégeles" en colaboración con "Civértice” y el Defensor del Menor de la Comunidad de Madrid, que titulada Videojuegos, menores y responsabilidad de los padres, muestra datos muy preocupantes relacionados con el uso incontrolado de videojuegos violentos por los menores. Se realizó mediante 4.000 encuestas aplicadas a menores de ambos sexos de edades comprendidas entre los 10 y 17 años. De los muchos datos que ofrece este informe destaca el hecho de que el $37 \%$ de los menores manifiesten su preferencia por los videojuegos de lucha frente a aquellos otros de naturaleza deportiva (39 \%) o de aventura (45\%). Al preguntarles sobre la capacidad de los videojuegos para estimular conductas violentas, un $11 \%$ consideran que los video-

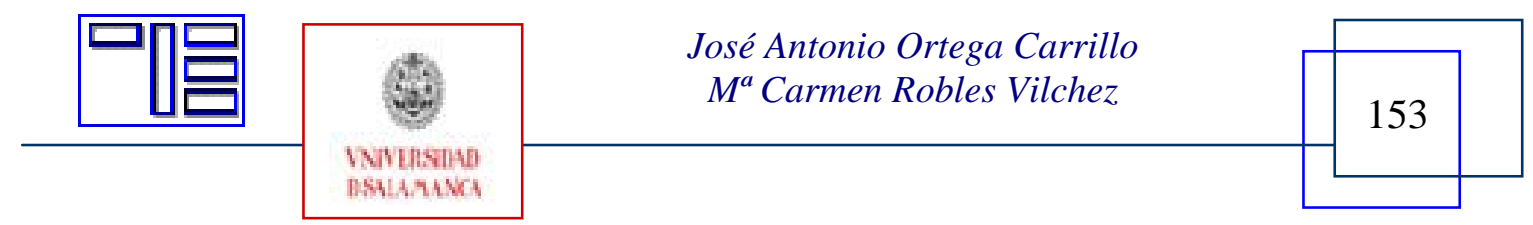


juegos pueden hacerles más violentos. Este dato, unido al confesado sobre su preferencia por los videojuegos violentos, da pie para valorar el alcance del problema social al que nos enfrentamos. En efecto, un $57 \%$ de los menores reconoce jugar con videojuegos en los que se daña, tortura o mata a otras personas y un $20 \%$ de ellos, reconoce jugar con títulos en los que se daña, tortura o mata a niños, ancianos o embarazadas. Igualmente, un $15 \%$ juega con títulos en los que se reproduce de forma interactiva la violencia hacia las mujeres.

Este sombrío panorama de uso de videojuegos que promocionan contravalores relacionados con la violencia y la guerra no favorece la ansiada Cultura de Paz que viene propugnando la UNESCO desde el seno del sistema de Naciones Unidas (a lo largo de sus más de sesenta años de existencia). Esta nueva forma de convivencia basada en la erradicación de la cultura de la fuerza y su sustitución por la fuerza del diálogo, se pretende impulsar con la promulgación en 2005 de la Ley 27 de Fomento de la Educación y la Cultura de Paz. La citada norma enarbola a los cuatro vientos que, "la Cultura de Paz la forman todos los valores, comportamientos, actitudes, prácticas, sentimientos y creencias que acaban conformando la Paz (...) Esta Cultura de Paz se tiene que implantar a través de potenciar la Educación para la Paz, la no-violencia, y los Derechos Humanos, a través de la promoción de la investigación para la paz, a través de la eliminación de la intolerancia, a través de la promoción del diálogo y de la no-violencia como práctica a generalizar en la gestión y transformación de los conflictos”.

Comprar videojuegos violentos a niños y adolescentes o tolerar su uso de forma irresponsable e impune, son acciones de dudosa calidad moral, si se entiende que la escuela y la familia son agencias que promueven la extensión de la Cultura de Paz y no violencia. El avance de resultados de la investigación que presentamos en este trabajo, resalta de manera inequívoca la opinión de los futuros docentes sobre el escaso y en muchos casos o nulo valor ético-educativo de los videojuegos violentos analizados, detectando la abundancia de actitudes negativas y contravalores que transmiten al videojugador, cuestión especialmente preocupante cuando esta tarea la realizan sujetos de edades tempranas que fácilmente confunden ficción y realidad. Tales efectos pudieran debilitar la necesaria adquisición de asideros morales que han de procurar la educación familiar y escolar.

\section{1.- VIDEOJUEGOS VIOLENTOS Y SUJETOS EN SITUACIÓN DE RIESGO SOCIAL}

Investigaciones aún escasas, comienzan a poner de manifiesto la existencia ciertos efectos perniciosos desencadenados por el uso frecuente y compulsivo de videojuegos violentos. Acaso la que mayor repercusión haya tenido en la comunidad científica sea la codirigida por Vincent P. Mathews (2006), Profesor de Radiología y Jefe de Neuroradiología en la Escuela de Medicina de la Universidad de Indiana. Los investigadores dirigidos por Mathews, invitaron de forma aleatoria a 44 adolescentes a que jugaran a videojuegos violentos o no violentos durante 30 minutos. Tras ello, los científicos utili-

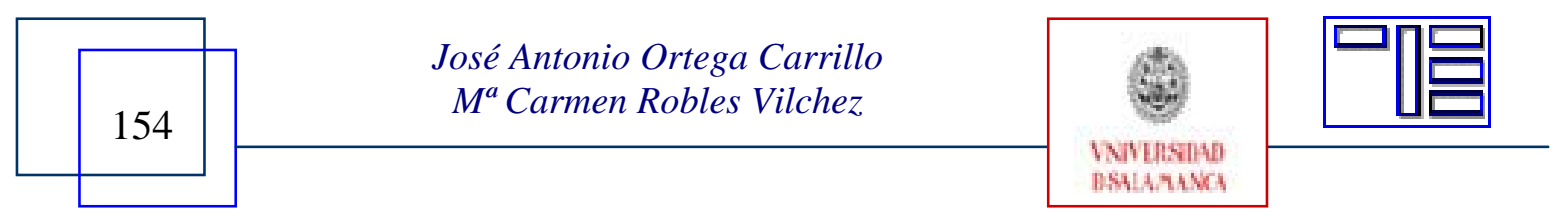


zaron imágenes de resonancia magnética funcional para estudiar el comportamiento cerebral de estos chicos durante una serie de tareas que medían el grado de inhibición y de concentración. Una de las pruebas empleaba estímulos emocionales y la otra no. En comparación con el grupo que jugó con el videojuego no violento, aquellos chicos que jugaron con videojuegos violentos mostraron una menor activación de las zonas prefrontales del cerebro que participan en la inhibición, la concentración y el autocontrol, y una mayor activación de la amígdala, una zona del cerebro involucrada en la activación emocional. Durante las tareas que requerían concentración y procesamiento de los estímulos emocionales, los adolescentes que jugaron con videojuegos violentos mostraron diferencias claras en la activación cerebral en comparación con los adolescentes que jugaron con un videojuego divertido y excitante, pero no violento.

La existencia de tales evidencias pone de manifiesto que los adolescentes con desórdenes de comportamiento tienen la estructura del cerebro y sus patrones de activación diferentes a los adolescentes que no padecen trastornos agresivos. Entre los estudiados están el desorden desafiante de oposición, caracterizado por hostilidad, hiperactividad, impulsividad, desafío a la autoridad y agresión verbal, y el desorden de conducta, determinado por conductas de crueldad manifiesta hacia animales y personas, violencia física, agresión sexual, abuso de drogas, uso de armas y otros comportamiento antisociales similares. En resumen, los trabajos de Mathews y sus colaboradores demuestran que los adolescentes agresivos con diagnostico de desórdenes de comportamiento utilizan sus cerebros de diferente manera que los adolescentes no agresivos, cuando interactúan con vídeo juegos violentos, pudiéndose atribuir tales variaciones a la existencia de diferencias en la estructura real del cerebro.

Recurriendo a las hemerotecas es fácil localizar una decena de casos de resonancia internacional en los que los medios de comunicación han atribuido al uso compulsivo de videojuegos violentos cierta de influencia patológica en el desarrollo de las conductas delictivas de sus autores (crímenes individuales y grupales y matanzas colectivas), si bien no tenemos constancia de la existencia hasta la fecha estudios empíricos que demuestren tal relación causa-efecto.

\section{2.- VIDEOJUEGOS Y APRENDIZAJE DE ACTITUDES, VALORES Y CON- TRAVALORES}

Genéricamente, las actitudes han sido categorizadas como disposiciones de ánimo, constructos psicológicos explicativos de la consistencia de la conducta; formas concretas de comportamiento ante la realidad, motivadas y fundamentadas por unos valores; estados mentales de disposición para responder y, evaluaciones, favorables o desfavorables de la realización de una conducta, (González Lucini, 1990 y Llopis y Ballester, 2001).

Íntimamente relacionados con las actitudes, y concebidos como cualidades, perfecciones, presentaciones cognitivas o creencias duraderas, los valores, provocan nuestra es-

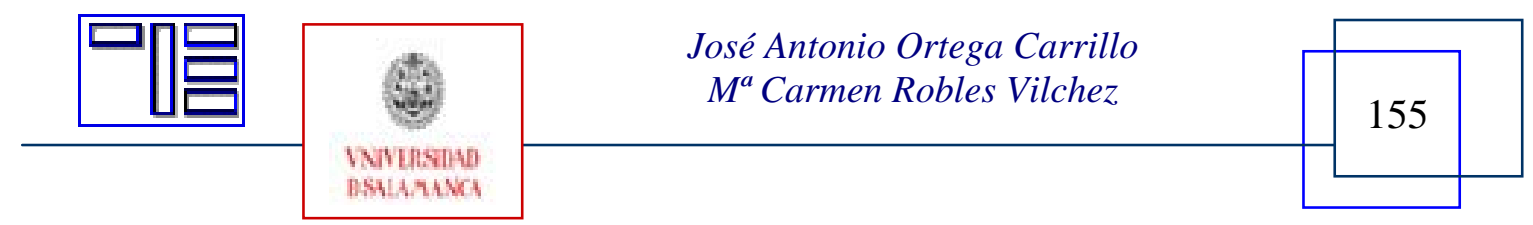


timación, nos posicionan ante objetos y nos aportan un marco de referencia existencial (Quintana, 1988, Gervilla, 2000 y Cruz Pérez, 2008).

Cual agencias de educación informal, los medios de comunicación ejercen una poderosa influencia en los procesos de conformación de actitudes, valores, creencias y mitos, así como en el aprendizaje de conceptos, hechos, principios, automatismos, habilidades y destrezas (Ortega Carrillo, 1997). Como potentes medios de naturaleza tecnológicodigital, el uso de videojuegos puede producir dos tipos de beneficios: La dimensión socioafectiva que supone la dinamización de las relaciones de grupo y del trabajo colectivo basada en la reflexión sobre contenidos que se materializa en conductas y valores aplicables a conductas cotidianas y, su contribución al desarrollo de destrezas y habilidades tales como la coordinación óculo-manual, el desarrollo de la especialidad, el control psicomotriz, la resolución de problemas, el desarrollo de la imaginación, el pensamiento, la memoria y el tratamiento de la información, (Aguiar y Farray, 2003: 35).

Dentro de la comunidad científica española destacan los estudios del equipo F9, dirigido por la profesora Begoña Gros. En su última obra colectiva titulada "Videojuegos y aprendizaje” (2008), los autores narran diversas experiencias de utilización escolar de los videojuegos como recurso de aprendizaje, justificando las ventajas de su integración curricular.

Los estudios sobre videojuegos y su repercusión en la conformación de valores son aún escasos y poco significativos. El Grupo de Investigación Tecnología Educativa e Investigación Social (TEIS) de la Universidad de Granada, que dirige el profesor Ortega Carrillo es uno de los pocos ejemplos de inclusión entre sus líneas prioritarias de investigación de esta temática (Ortega Carrillo, 2001 y 2003 y Pascual y Ortega, 2007). Los trabajos de Vera y Espinosa (2003) también la abordan, resaltando el poder de los videojuegos para transmitir actitudes y conformar valores y alertando sobre el peligro que supone el uso incontrolado de estos materiales tecnológicos (especialmente los que reproducen argumentos violentos), por parte de niños y adolescentes cuya capacidad crítica es escasa y cuyos asideros morales pueden ser exiguos. Para estas autoras, "es preciso ser consciente de qué valores se transmiten y promocionan en los ratos de ocio, determinar que niños o jóvenes pueden quedar más impresionados por estos mecanismos lúdicos, y decidir cómo canalizar las secuelas del impacto que producen en su sensibilidad” (pág.51).

Para profundizar en esta polémica influencia, parece aconsejable incrementar la cultura evaluadora de profesorado y familias. Para ello, Del Moral (2003: 57-61), plantea una estrategia de análisis de videojuegos basada en la convergencia de aspectos educativos (objetivos, temática, ámbito de incidencia, tratamiento, lenguaje y elementos didácticos); psicológicos (conductismo, constructivismo, aprendizaje social, etc.); sociológicos (personales, roles, valores y mensajes explícitos e implícitos); estéticos (decorado, ambientación, vestuarios, colorido) y técnicos (estructura interna, interfaz, animación, realización y montaje e interactividad).

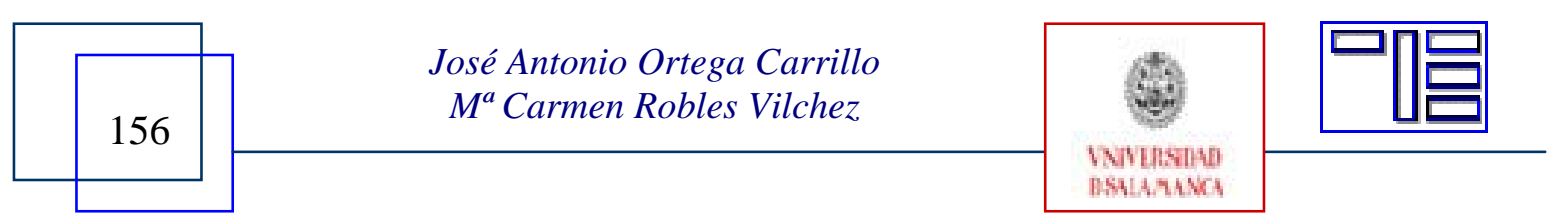


En este mismo sentido hemos propuesto Ortega (2001 y 2003) y Pascual y Ortega (2007) una escala de análisis de videojuegos para uso familiar y escolar, cuya aplicación ha dado pié a la investigación que se presenta en este trabajo.

\section{3.- PRÁXIS DE LA EVALUACIÓN INTEGRAL DE VIDEOJUEGOS COMER- CIALES}

El propósito de la investigación cuyo avance de resultados presentamos es doble. Por un lado, se trata de ejercitar a los futuros docentes en formación en habilidades profesionales relacionadas con la evaluación del potencial educativo de materiales multimedia y, por otro, fomentar el trabajo colaborativo y el debate grupal sobre las actitudes positivas y valores y contravalores y actitudes negativas que transmiten a niños y adolescentes los videojuegos.

En el desarrollo de la experiencia han actuado como evaluadores el alumnado de un grupo clase de tercer curso de la Diplomatura de Magisterio de Educación Primaria de la Facultad de Ciencias de la Educación de la Universidad de Granada, formado por 91 sujetos de edades comprendidas entre los 20 y 23 años, de las cuales 76 eran mujeres y 15 hombres.

Para realizar tal evaluación dicho alumnado se reunió en grupos de 4-5 componentes, constituidos, con los siguientes criterios:

- Uno debía ser videojugador activo y dominar bien el videojuego elegido, disponiendo de los medios tecnológicos necesarios para ejecutarlo con los demás componentes, cuantas veces fuera necesario.

- Otro participante no debía tener experiencia alguna en el campo de los videojuegos.

- El resto podrían ser videojugadores ocasionales o no videojugadores.

\subsection{Videojuegos estudiados y pauta de análisis}

Los 15 videojuegos analizados han ocupado, y en muchos casos siguen ocupando, altas posiciones en las listas de ventas en los últimos años. Los títulos seleccionados y su sinopsis argumental aparecen reflejados en la siguiente tabla:

\begin{tabular}{|l|l|}
\hline $\begin{array}{c}\text { Título del videojue- } \\
\text { go }\end{array}$ & \multicolumn{1}{c|}{ Sinopsis } \\
\hline Resistance & $\begin{array}{l}\text { Acabar con una especie mutante creada por el virus Quimera, que em- } \\
\text { prende la conquista de Europa. }\end{array}$ \\
\hline $\begin{array}{l}\text { Grand Theft Auto } \\
\text { IV }\end{array}$ & Asesinar a sueldo en un negocio ilegal de taxis. \\
\hline Tekken 4 & $\begin{array}{l}\text { Vengar a un hijo (reencarnado en diablo) que murió en brazos de su } \\
\text { padre. }\end{array}$ \\
\hline Grod of War & Sangrienta epopeya inspirada en la mitología griega. \\
\hline
\end{tabular}

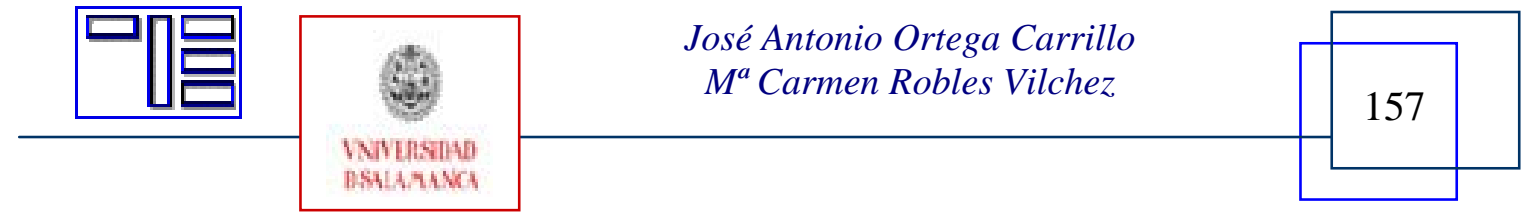


Revista Electrónica Teoría de la Educación.

Educación y Cultura en la Sociedad de la Información.

http://www.usal.es/teoriaeducacion

Vol. 9. No 3. Noviembre 2008

\begin{tabular}{|l|l|}
\hline Call Of Duty 3 & Misiones bélicas en la Segunda Guerra Mundial. \\
\hline Assin's Creed & $\begin{array}{l}\text { En la época de las cruzadas el jugador inicia una huida después de ma- } \\
\text { tar al verdugo de unos ahorcados. }\end{array}$ \\
\hline Dragon Ball Z & $\begin{array}{l}\text { Luchadores que usan su fuerza física y mental para acabar con el mal de } \\
\text { forma mágica. }\end{array}$ \\
\hline Resident Evil 4 & $\begin{array}{l}\text { Rescatar a la hija del presidente de los Estados Unidos que ha sido rap- } \\
\text { tada por un grupo no identificado, una secta. }\end{array}$ \\
\hline Medal of Honor & $\begin{array}{l}\text { En la Guerra del Pacífico, el jugador va neutralizando a los soldados del } \\
\text { ejército rival. }\end{array}$ \\
\hline Princes of Persia & $\begin{array}{l}\text { En una tierra de mitos y leyendas, el jugador deberá detener al Dios de } \\
\text { la Oscuridad que ha liberado a las fuerzas del mal e intenta sumir al } \\
\text { mundo en la oscuridad. }\end{array}$ \\
\hline Mortal 4 Kombat & $\begin{array}{l}\text { Competir en un torneo en el que se enfrentaran los mejores guerreros de } \\
\text { la tierra contra los fieros guerreros del Outworld que intentan vencer en } \\
\text { el torneo para invadir y gobernar la tierra. }\end{array}$ \\
\hline Gears of War & $\begin{array}{l}\text { Librar una guerra interplanetaria entre naciones por el control de una } \\
\text { sustancia llamada Emulsión que puede convertirse directamente en } \\
\text { energía mediante el proceso de Lightmass. }\end{array}$ \\
\hline Leisure Suit Larry & $\begin{array}{l}\text { Lograr que el protagonista (Larry) mantenga relaciones sexuales fre- } \\
\text { cuentando lugares de vicio y corrupción. }\end{array}$ \\
\hline Red Steel & Luchar contra las mafias japonesas. \\
\hline Starcraft & $\begin{array}{l}\text { Seleccionar una raza para llevarla a la victoria realizando diferentes } \\
\text { misiones y objetivos. }\end{array}$ \\
\hline
\end{tabular}

La pauta para la valoración crítica del contenido ético, estético y educativo de videojuegos, de elaboración propia (Ortega, 2003) y usada en esta investigación, está compuesta por treinta indicadores cuyo contenido se describe a continuación:

- Como datos preliminares el evaluador rellena una ficha técnica en la que se especifica el título y subtítulo, la empresa creadora, el idioma, el número de jugadores, la edad mínima recomendada, él género, los requisitos técnicos mínimos, el año de aparición de la versión, el contenido de la portada, contraportada y pastas interiores y la posibilidad de jugar en red.

- La primera parte de la pauta, ayuda a analizar morfosintáctica y estéticamente el videojuego y está formada por siete indicadores que ayudan a reflexionar sobre: El argumento (historia/as que aparecen en el desarrollo temático del videojuego y contenido de las escenas (trailer) que pueden aparecer introduciendo, aclarando o reforzando el argumento de las diversas etapas; las acciones que realiza el jugador en el desarrollo del videojuego; la caracterización de cada uno de los personajes (aspecto, vestimenta, iluminación, utensilios, rol y estatus social, gestos y acciones que realiza, rasgos sexuales, etc.); la descripción de la escenografía en la que se desarrolla la historia/as (ambientación histórica, fondos, elementos naturales, mensajes publicitarios, elementos móviles), así como de pasajes musicales, monólogos y diálogos orales y textos escritos.

- La segunda parte de este instrumento, ayuda a la realización de un análisis semántico e interpretativo, en clave psicopedagógica del videojuego selecciona-

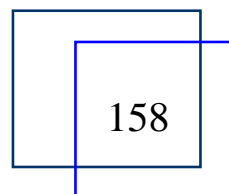

José Antonio Ortega Carrillo $M^{a}$ Carmen Robles Vilchez

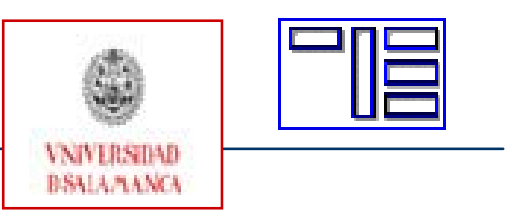


do. Contiene otros siete indicadores referidos a la interpretación de los significados presentes y latentes (simbólicos y subliminales) de las distintas etapas del argumento del videojuego; de las acciones que realiza el jugador; de los personajes; de los diferentes elementos que componen la escenografía; de los pasajes musicales, monólogos y diálogos orales y textos escritos; de los resultados parciales (logros) que permiten ir avanzando en la acción, y finalmente, del resultado final del videojuego.

- La tercera parte, invita a realizar un análisis afectivo-emocional, estando compuesto por cinco indicadores que aluden a la descripción de las relaciones emotivas y afectivas que aparecen en los comportamientos de los protagonistas y demás personajes entre sí; aquellas que siente el jugador al leer la información que aparece en la caja del videojuego y al ver su introducción; las que experimenta en el transcurso del mismo y al finalizarlo y, las posibles razones emotivas por las que el videojugador desea volver a iniciar el juego, (su potencial capacidad adictiva).

- La cuarta parte, y más importante, ayuda a realizar una valoración ética (actitudes y valores) que puede desencadenar y promover este producto tecnológico y está formada por diez indicadores. Para facilitar esta tarea se ofrece además un listado, formado por 62 actitudes y valores con sus correspondientes actitudes negativas y contravalores, expresados de forma, un tanto antinómica, para ayudar a la toma de decisiones. Tales indicadores que ayudan a identificar la escala axiológica que induce la lectura de la información visual y escrita de la caja que contiene el videojuego; el análisis de la historia o historias en las que sumerge al jugador durante la acción; el estudio de las acciones que realiza el jugador; la determinación del vestuario y aspecto físico de los personajes y de los escenarios de tales acciones; el análisis de las actuación de los diversos personajes que intervienen en la historia/s y de los roles sociales que asumen; el estudio del contenido de los monólogos, diálogos, efectos sonoros, pasajes musicales y textos que acompañan a las etapas y acciones que suceden en el videojuego y, aquellos valores que se derivan del sistema de obtención de puntos al avanzar en el desarrollo del videojuego y al finalizar con éxito éste.

- La parte final de la pauta ofrece la posibilidad de reflexionar de manera libre y abierta sobre otros aspectos de interés socioeducativo. Invita a realizar un juicio sobre la utilidad educativa del videojuego, sobre la edad mínima recomendada de uso y la coherencia del código PEGI con su contenido; propone determinar la Información mínima que debería aparecer en el etiquetado del producto (caja envoltorio) para que familiares y usuarios conozcan su contenido real y, plantea la posibilidad de analizar críticamente el contenido de las webs existentes sobre el videojuego en cuestión.

\subsection{Algunos resultados obtenidos}

En este trabajo analizaremos los resultados referidos a las actitudes, valores y contravalores detectados por los evaluadores en los videojuegos sometidos a estudio en lo relati-

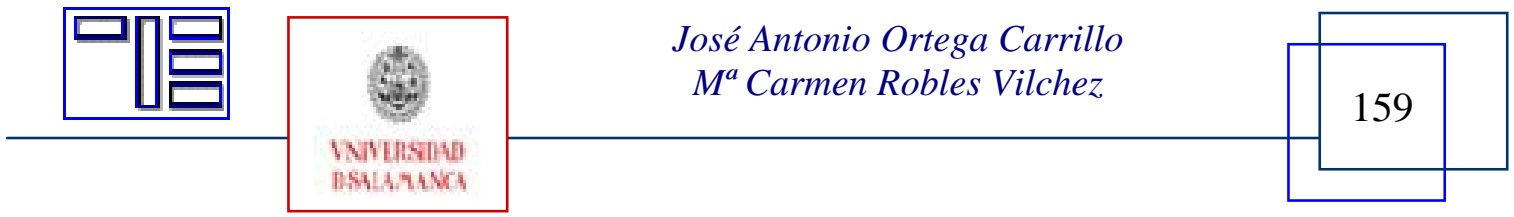


Revista Electrónica Teoría de la Educación.

Educación y Cultura en la Sociedad de la Información.

http://www.usal.es/teoriaeducacion

Vol. 9. No 3. Noviembre 2008

vo a su argumento, a los roles de los personajes que los protagonizan, a las acciones que realiza el videojugador en el transcurso de la aventura, a los resultados parciales y al resultado final.

$\mathrm{Al}$ analizar el argumento los evaluadores han consignado la presencia de 30 actitudes positivas y valores y 38 actitudes negativas y contravalores, de los 62 consignados en la escala suministrada, lo que inclina la balanza hacia la axiología negativa. Las tres actitudes y valores que con mayor frecuencia se han repetido han sido, la capacidad de superación, el sentido de perfeccionamiento y la sana competencia. Por su parte, las actitudes negativas y contravalores más frecuentes en al análisis argumental han sido el fomento de la violencia, la resolución agresiva de conflictos, el egocentrismo y la insolidaridad, como muestran estas gráficas:
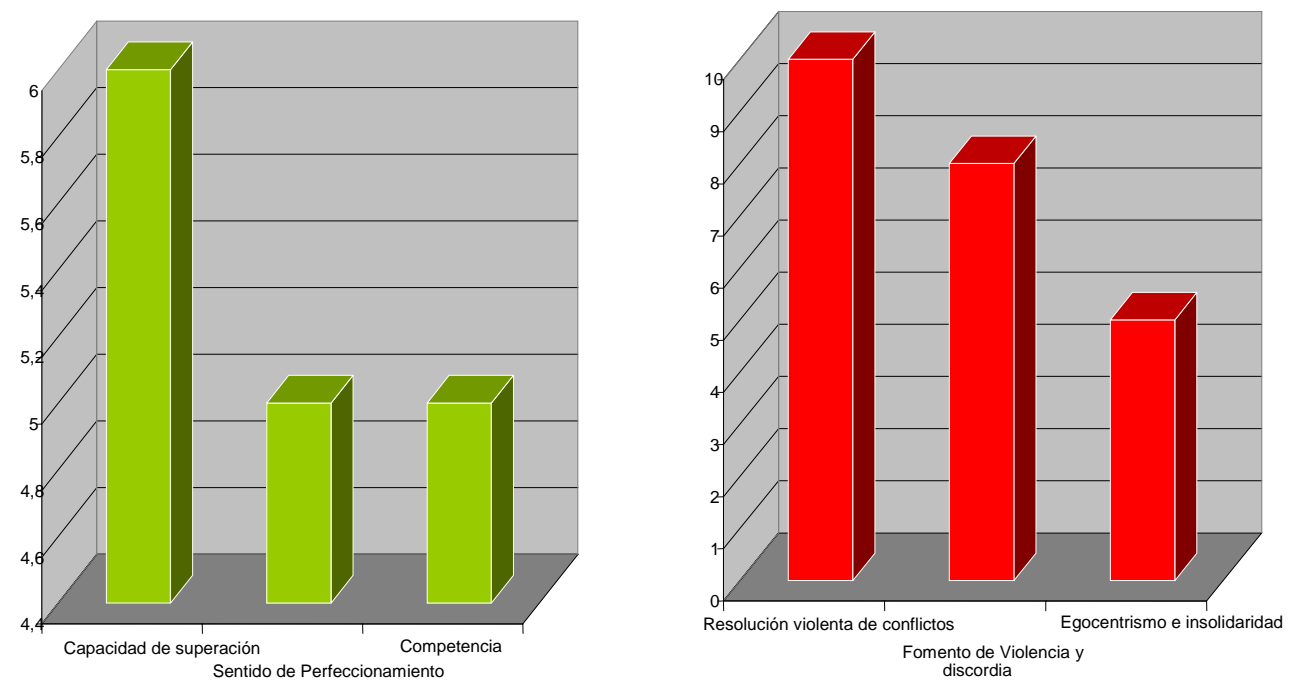

Fig. 1. Actiudes, valores y contravalores más reseñados en el análisis del argumento.

Al estudiar el rol de los personajes, se detectaron 24 actitudes y valores y 37 actitudes negativas y contravalores. Las tres actitudes y valores que con mayor frecuencia se han repetido en el rol de los protagonistas son la lealtad, la tendencia a evolucionar y la sana competencia. Por su parte, las actitudes negativas y contravalores más frecuentes han sido el fomento de la violencia, la discordia, la imposición basada en fuerza física o psicológica y la resolución violenta de conflictos, tal como muestran las gráficas adjuntas:
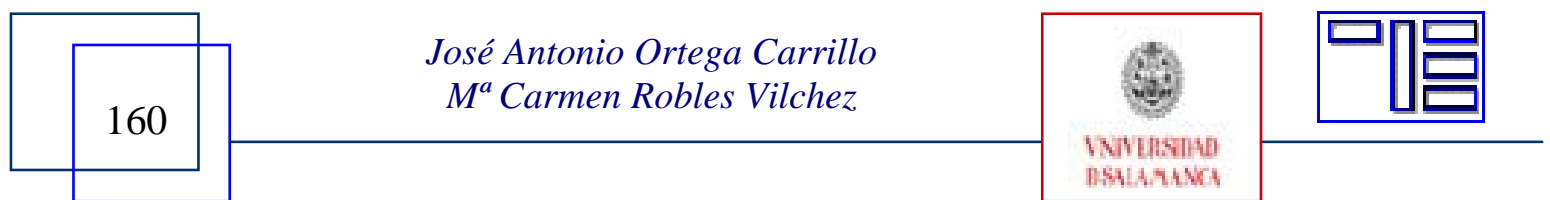

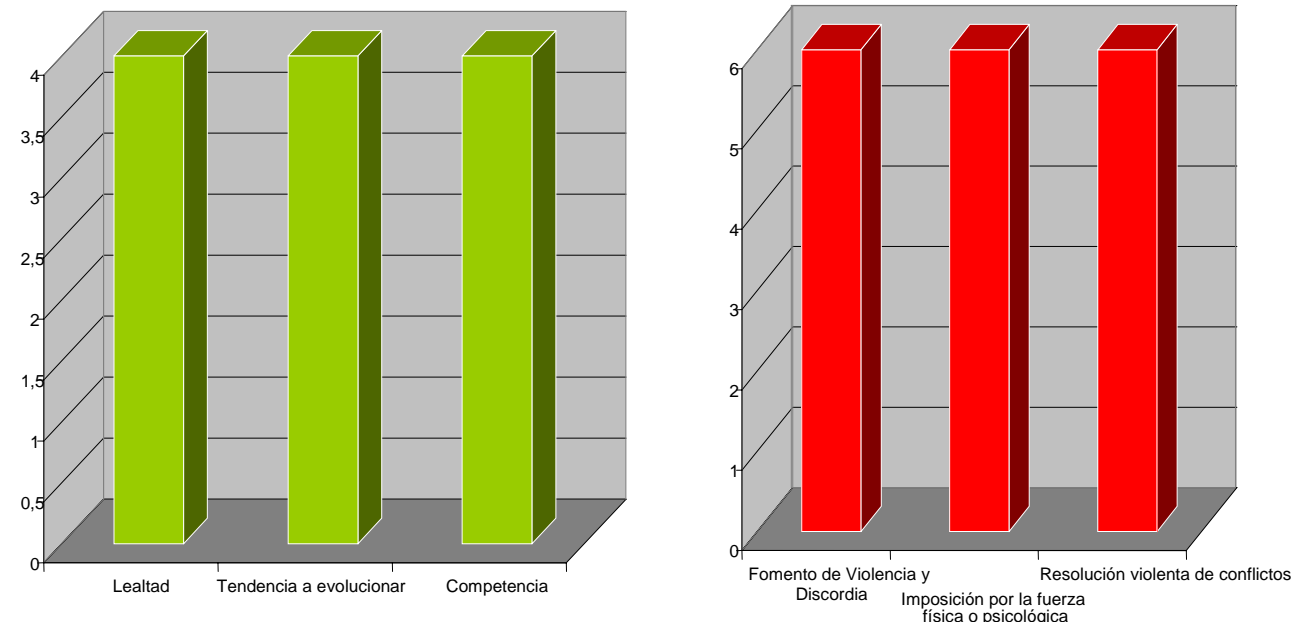

Fig. 2. Actitudes, valores y contravalores más reseñados en estudio del rol de los personajes.

Cuando los grupos reflexionaron sobre las acciones que realiza el jugador fueron 33 las actitudes positivas y valores detectados, frente a 39 actitudes negativas y contravalores. Las tres que con mayor frecuencia se han repetido son el sentido del perfeccionamiento, la tendencia a evolucionar y la confianza. Por su parte, las actitudes negativas y contravalores más frecuentes han sido el fomento de la violencia y la discordia, la imposición basada en fuerza física o psicológica y la resolución violenta de conflictos, como reflejan estas gráficas:
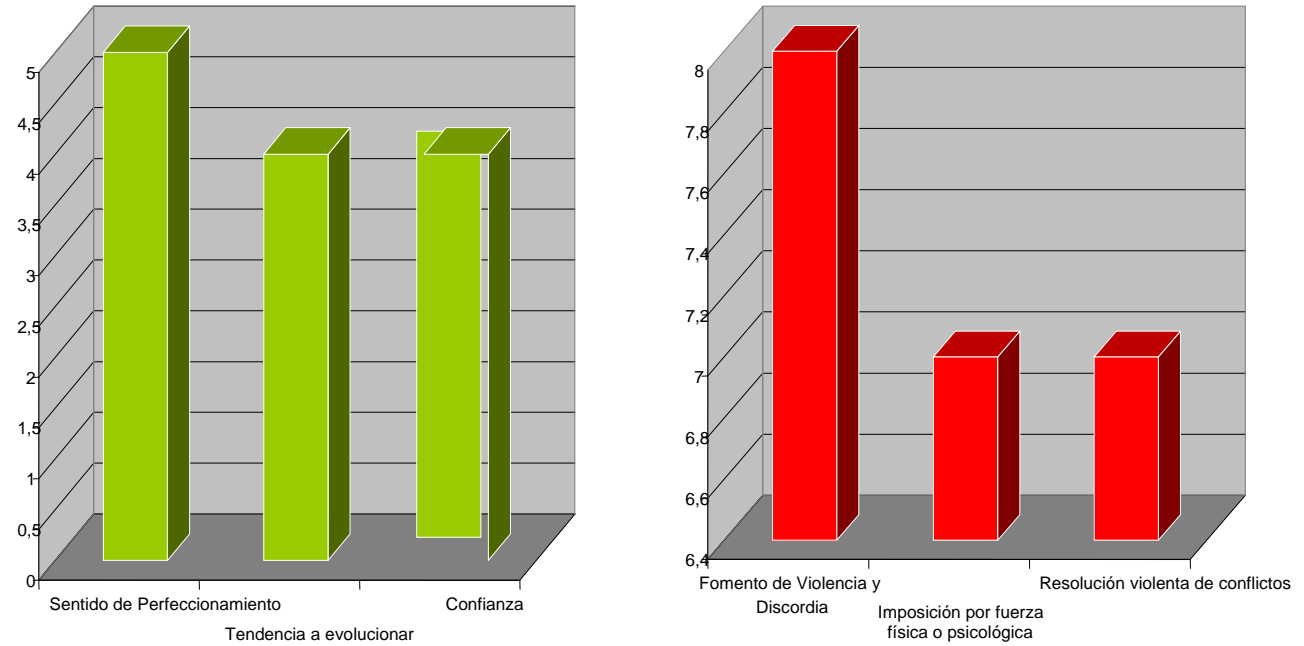

Fig. 3. Actitudes, valores y contravalores más reseñados en las acciones de los personajes.

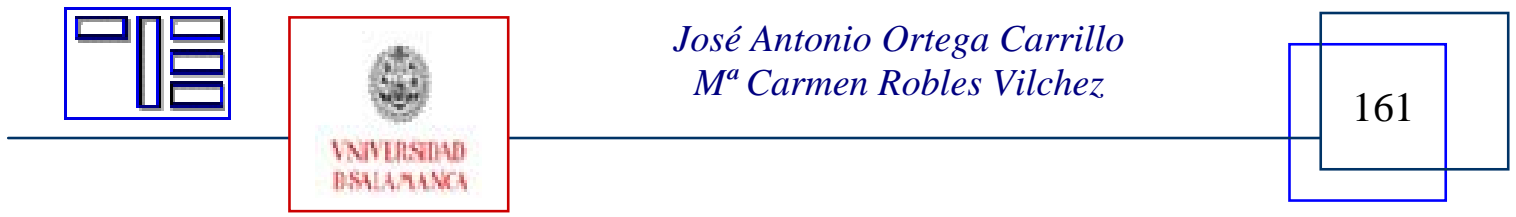


Revista Electrónica Teoría de la Educación.

Educación y Cultura en la Sociedad de la Información.

http://www.usal.es/teoriaeducacion

Vol. 9. No 3. Noviembre 2008

Al debatir los resultados parciales, los evaluadores detectaron la presencia de 21 actitudes positivas y valores y 23 actitudes negativas y contravalores, lo que inclina muy ligeramente el balance hacia la axiología negativa. Las tres actitudes y valores más frecuentes son el sentido del perfeccionamiento, la alegría y el optimismo. Las actitudes negativas y contravalores más detectas han sido el fomento de la violencia, la discordia, la resolución violenta de conflictos, el desprecio y la intolerancia, tal como reflejan las siguientes gráficas:
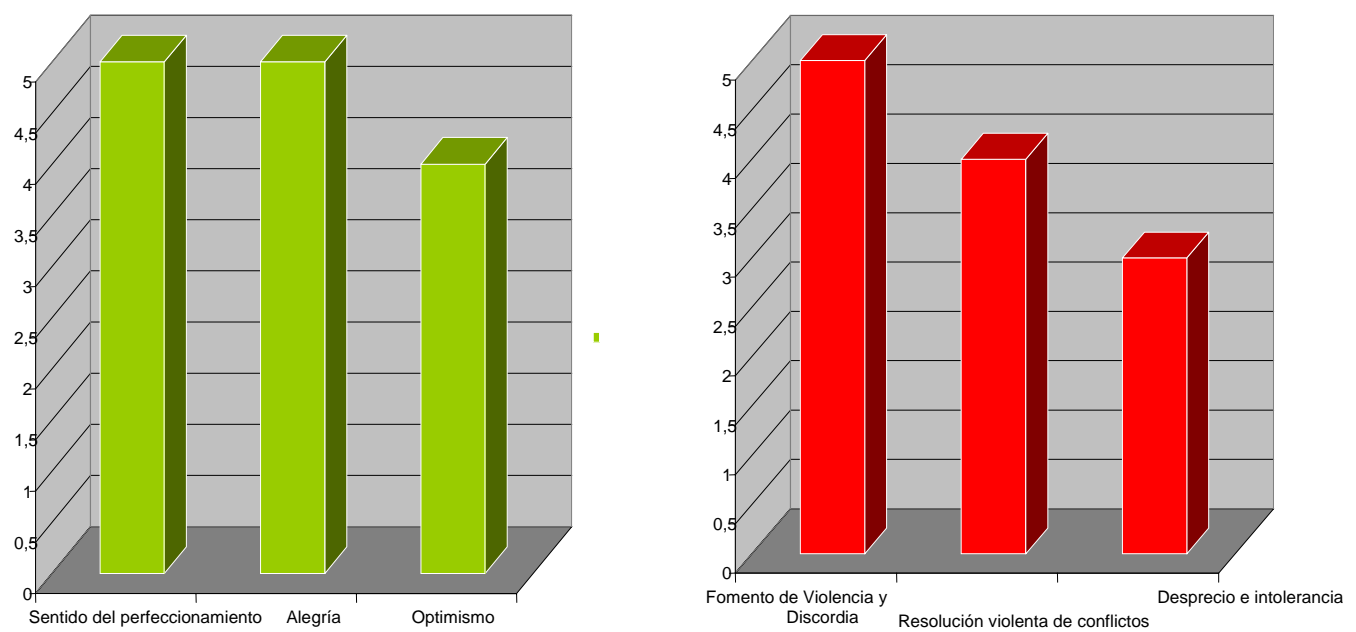

Fig. 4. Actitudes, valores y contravalores más reseñados al estudiar los resultados parciales.

Finalmente, al estudiar los resultados finales, se determinaron 20 actitudes y valores y 28 actitudes negativas y contravalores. Las positivas más repetidas son la alegría, el sentido del perfeccionamiento y la sana competencia. Las negativas más frecuentes han sido fomento de la violencia y la discordia, la imposición basada en la fuerza física o psicológica, el desprecio y la intolerancia, como se ve en las gráficas adjuntas:

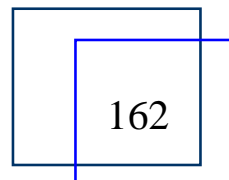

José Antonio Ortega Carrillo $M^{a}$ Carmen Robles Vilchez 

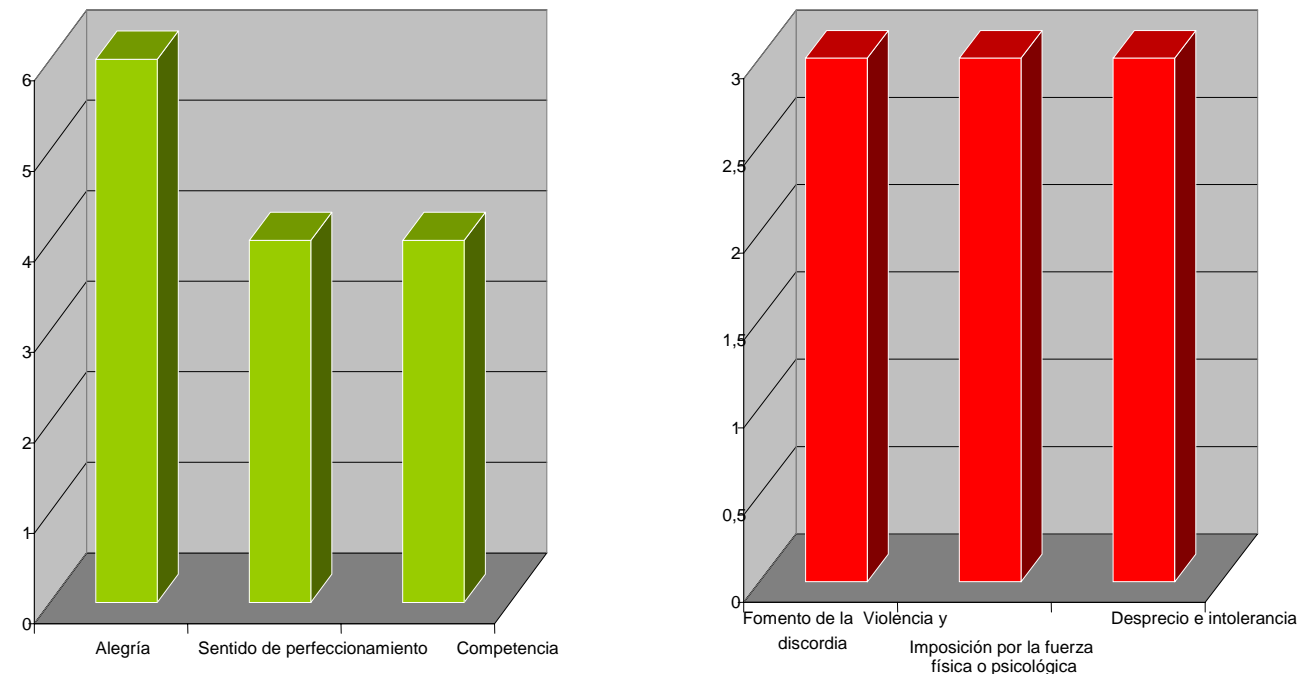

Fig. 5. Actitudes, valores y contravalores más reseñados al analizar los resultados finales.

\section{4.- CONCLUSIONES}

Una visión sumativa de las especificidades axiológicas descritas por los jueces en los ámbitos estudiados se expresa en el siguiente gráfico, que muestra las diez actitudes y valores más referenciados en el estudio:



Fig. 6. Actitudes positivas y valores más reseñados por los equipos evaluadores.

Nótese que las actitudes y valores reflejados conforman un cuadro axiológico asumible, tanto desde el punto de vista de la ética civil que propone la Declaración Universal de Derechos Humanos y la Carta de Derechos del Niño, como desde la pespectiva moral de los grandes credos monoteistas.

La polémica surge cuando se analizan estas actitudes y valores en el contexto argumental de este tipo de videojuegos, en los que son frcuentes las matanzas, violaciones, acciones perversas de mafias y sectas y en los que se subraya la

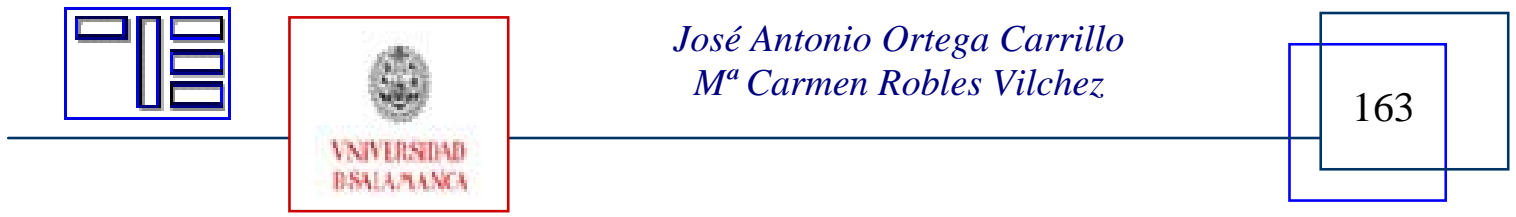


superioridad de unas civilizaciones sobre otras, etc. Ser perfecto, superarse, alegrarse y ser competente para matar, aniquilar, destruir, robar o violar, es una perversión moral, inasumible desde el punto de vista educativo. Igualmente ser leal, tener confianza y mostrar responsabilidad frente a quienes ejercen tales vilezas, resulta igualmente incoherente y abyecto, para el desarrollo de una ciudadanía saludable y éticamente responsable.

Por tal motivo, pensamos que tales actitudes y valores han de contemplarse como antitudes negativas y contravalores, y por ello dejan de tener oportunidad. Por ello, conviene subrayar su capacidad potencial de pervertir las conductas de ciertos colectivos de niños y adolescentes que, con escasos asideros morales y en muchos casos con carencias afectivas y de sociabilidad, tienen dificultades para distinguir entre ficción y realidad cuando están sumergidos muchas horas a la semana en el universo adictógeno que generan este tipo de videojuegos. Tales argumentos se refuerzan cuando repensamos los diez contravalores más reflejados en los juicios emitidos por el centenar de los evaluadores y que refleja el siguiente gráfico:

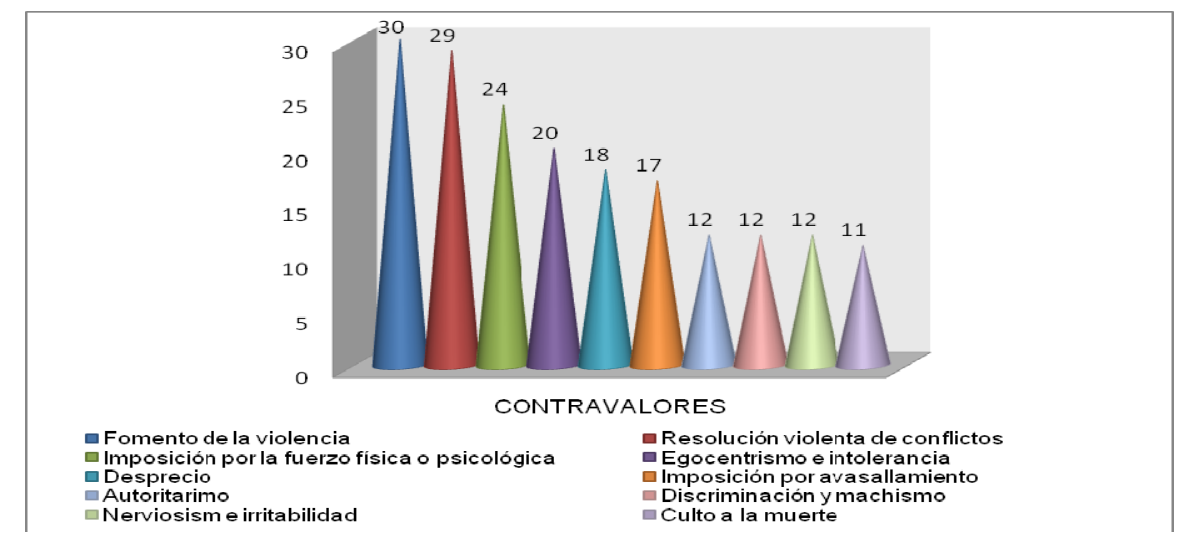

Fig. 7. Actitudes negativas y contravalores más reseñados por los evaluadores.

Tal decálogo de actitudes negativas y contravalores en un potente caldo de cultivo para crear confusión, al irrumpir negativamente en los procesos de conformación del carácter de los menores que, padeciendo episodios adictógenos, practican compulsivamente el consumo de videojuegos violentos.

\section{5.- BIBLIOGRAFÍA}

AGUIAR, M. V. Y FARRAY J. I. (2003). “Los videojuegos”. Comunicación y Pedagogía, 191, 33-36.

BOLETIN OFICIAL DEL ESTADO (2005). Ley 27/2005 de 30 de noviembre de fomento de la Educación y la Cultura de Paz. Madrid: Boletín Oficial del Estado, 287: 39418-39419.
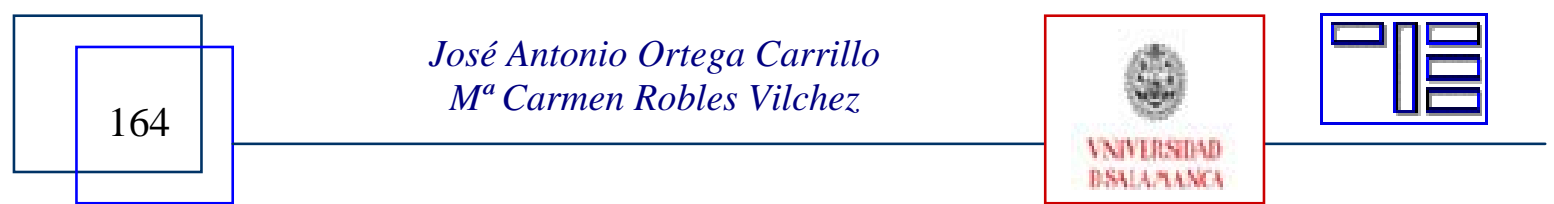
CÁNOVAS, G. (Coord), (2005). “Videojuegos, menores y responsabilidad de los padres”. Disponible en línea: http://www.guiavideojuegos.es/estudio.pdf. Madrid: Defensor del Menor de la Comunidad de Madrid-Protégeles-Cevertice. Consultado el 12-62008.

DEL MORAL, M. E. ( 2003). “Análisis de los videojuegos desde la convergencia de aspectos psico-educativos, técnicos y estéticos”. Comunicación y Pedagogía, 191, 57-65.

FERZZOLA, M. (2007). “Historia de la violencia en los videojuegos”. Diario El País (226-2007). Disponible en línea:

http://www.elpais.com/articulo/internet/videojuegos/violentos/historia/elpeputec/20070622elpepu net_3/Tes (Consultado el 26-6-2008).

GERVILLA, E. (2000). Valores del cuerpo educando. Herder. Barcelona.

GROS, B. (Coord.) (2008): Videojuegos y aprendizaje. Barcelona: Graó.

ORTEGA, J. A. (1997). Comunicación visual y tecnología educativa. Granada: Grupo editorial Universitario.

ORTEGA, J. A. (2001). “Análisis crítico de los valores que transmiten los videojuegos: Descubriendo su potenciar seductor de naturaleza subliminal”. En Lorenzo, M. y otros (Coordres.): Las organizaciones educativas en la sociedad neoliberal. Vol. III, pp. 2113-2118.

ORTEGA, J. A. (2003).Videojuegos y cultura de paz. Comunicación y Pedagogía, 191, 6771.

PÉREZ, C. (2008): “Sobre el concepto de valor”. Bordón, 60, 1, 99-112.

GONZÁLEZ, F. (1990). Educación en valores y diseño curricular. Madrid. Ahambra Logman.

LLOPIS E. y BALLESTER, F. (2001). Valores y actitudes en educación. Valencia: Tirant Lo Blanch.

MATHEWS, V. (2006). “Do Violent Video Games Change Teen Brains?” Disponible en línea.

http://www.research.indiana.edu/news/stories/0096_games.html. Universidad de Indiana. Consultado 12-6-2008.

PASCUAL, M. A. Y ORTEGA, J. A. (2007). “Videojuegos y Educación”. En J.A. ORTEGA Y A. CHACÓN (Coordres.): Nuevas Tecnologías para la educación en la era digital. Madrid: Pirámide, pp. 207-228.

QUINTANA J. M. (1980). Sociología de la Educación. Madrid: Edit. Biblioteca de Ciencias Sociales.

VERA, M. I Y ESPINOSA, D. (2003): “Los videojuegos y el aprendizaje de valores”. Comunicación y Pedagogía, 191, 48-52.

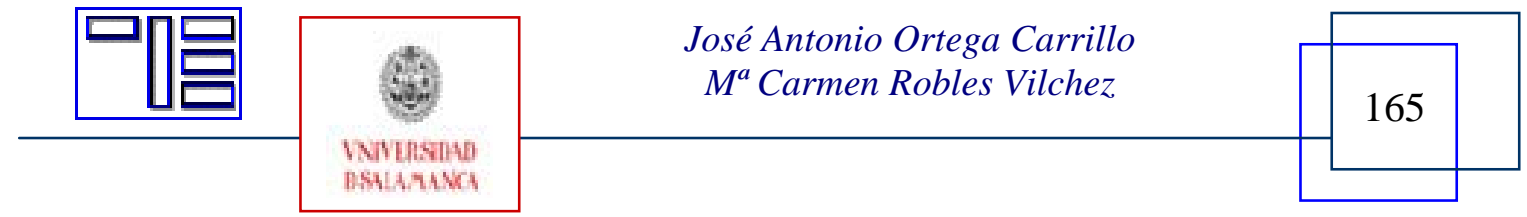


Revista Electrónica Teoría de la Educación.

Educación y Cultura en la Sociedad de la Información.

http://www.usal.es/teoriaeducacion

Vol. 9. No 3. Noviembre 2008

Para citar la presente editorial puede utilizar la siguiente referencia:

ORTEGA CARRILLO, José Antonio y ROBLES VILCHEZ, M ${ }^{\mathrm{a}}$ Camen (2008). Análisis axiológico-educativo de videojuegos de temática violenta. En SÁNCHEZ i PERIS, Francesc J. (Coord.) Videojuegos: una herramienta educativa del "homo digitalis” [monográfico en línea]. Revista Electrónica Teoría de la Educación: Educación y Cultura en la Sociedad de la Información. Vol. 9, $\mathrm{n}^{\circ}$ 3. Universidad de Salamanca [Fecha de consulta: $\mathrm{dd} / \mathrm{mm} /$ aaaa].

http://www.usal.es/ teoriaeducacion/rev_numero_09_03/n9_03_ortega_robles.pdf ISSN: 1138-9737

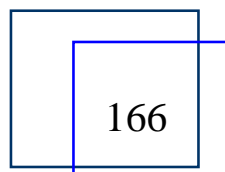

José Antonio Ortega Carrillo $M^{a}$ Carmen Robles Vilchez 